\title{
Electro Magnetic Wireline Retrievable-Surface Controlled Subsurface Safety Valve: A New Backup For Surface Controlled Subsurface Safety Valve To Avoid WorkOver
}

\author{
P. Imbò, eni E\&P., G Gandini, eni E\&P,
}

\section{$\underline{\text { Abstract }}$}

\section{The scope of this document} is to summarize the field trial of Expro FlowCaT ${ }^{\mathrm{TM}}$ and Geoservices GEM-Valve ${ }^{\mathrm{TM}}$

Wireless

Electromagnetic Surface Controlled Sub-surface Safety Valve in Fiume Treste field, in sud of Italyt and provide a final technical evaluation.

In 2007, COMP started a study about existing Surface Controlled Sub-surface Safety Valve, to have a complete knowledge of their status in worldwide wells and to make a statistic analysis of the most common failures.

The control line's failure is the most critical, since it prevents the installation of a contingency WRSCSSV, which would be impossible to control.
In these cases, the only available contingency, till now, was the installation of a SSCSV (SubSurface Controlled Safety Valve), but it doesn't guarantee the same level of reliability as the SCSSV's:

These valves are not controlled from the surface, they are not failsafe and they are operated by particular events on the well (such as high flow rate or low pressure), which are very uncertain.

To address this issue, COMP made a survey with valves' suppliers and a solution to, this problem was identified in the new wireless electromagnetic technology.

After a strict "ISO-modified" qualification process and a 6-months field installation in a STOGIT gas 
storage well with monthly tests and a final slam test, both the considered Electromagnetic Wireless Surface Controlled Sub-surface Safety Valves: Expro 3.65" FlowCaT ${ }^{\mathrm{TM}} \quad \&$ Geoservices 3.72" GEM-VALVE ${ }^{\mathrm{TM}}$ are considered qualified and field proven to be installed in eni wells.

\section{$\underline{\text { Introduction }}$}

$E_{\text {ni }}$ policies require the installation of a SCSSV as mandatory in all the new completed wells. It shall be Tubing Retrievable (Wireline Retrievable as a contingency), flapper type, rod piston operated and preferably not self equalizing (because of the risk it could self-open in case of leak at the control system).

In 2007 , COMP started a study about existing Surface Controlled Sub-surface Safety Valve, to have a complete knowledge of their status in worldwide wells and to make a statistic analysis of the most common failures.
It was discovered that among a population of 2835 TR-SCSSV installed, 300 had failures and 69 (23\%) of these had a failure to the control line.

The control line's failure is the most critical, since it prevents the installation of a contingency WRSCSSV, which would be impossible to control. The same situation is present in all the old wells completed without a control line for the SCSSV.

In these cases, the only available contingency, till now, was the installation of a SSCSV (Sub-

Surface Controlled Safety Valve), but it doesn't guarantee the same level of reliability as the SCSSV's: these valves are not controlled from the surface, they are not fail-safe and they are operated by particular events on the well (such as high flow rate or low pressure), which are very uncertain.

For these reasons "The SSCSV shall be considered only as back up of a SCSSV. The aim of 
such valves is to allow preparation to work-over or abandonment. Once the WR-SSCSV installation is required, an intervention program to restore the well integrity shall be immediately scheduled".

To address this issue, COMP made a survey with valves' suppliers and a solution to this problem was identified in the new wireless electromagnetic technology.

Two safety valves were considered to be suitable for Eni's needs:

Geoservices GEM-Valve ${ }^{\mathrm{TM}}$ and the Expro FlowCaT ${ }^{\mathrm{TM}}$.

\section{Geoservices EM SCSSV has} already been installed in some wells by other Oil Companies (without a complete ISO/API qualification process), while the Expro FlowCaT ${ }^{\mathrm{TM}}$ was at the prototype stage: the first prototype was used for laboratory tests and the second one is the one run in hole by Eni for the field test.

Both of the valves are: Surface Controlled, Fail Safe and Wireline retrievable.
They are based on similar technologies : an electromagnetic wireless signal is transmitted from a surface control panel to the wellhead and down through the tubing and the electric circuit is closed by ground (earth).

However, the two SCSSV have different designs: Geoservices applied the electromagnetic technology to an existing valve's design, which is a standard flapper type; meanwhile Expro had a completely new valve built by Petrowell: this valve is a "poppet" type, with two ceramic sealing elements acting against a radial flow.

\section{Expro Flowcat}

Expro FlowCat ${ }^{\mathrm{TM}}$ is a WSV developed by Expro and never installed in a well before.

This tool is a specifically designed WRSV "poppet type" equipped with the CaTS ${ }^{\mathrm{TM}}$ telemetry system, already being used for downhole data transmission . 
The CaTS $^{\text {TM }}$ is a wireless transmission system based on the capability to communicate with electromagnetic low frequency waves using the well's metallic profiles as a conductor and the ground to close the circuit.

The valve's body has been designed and built by Petrowell. Obviously, being the electronics and battery packs below the SCSSV itself, it is not full bore.

The downhole power supplied by the batteries is needed by the receiver to catch and interpretate the "stay open" signal, but it is not applied to effectively operate the valve; this is in order to save the battery life and improve their durability.

So the power to shift the sealing elements in open position shall be provided externally, applying pressure at the wellhead. This feature drives to some considerations concerning the nominal working pressure to be considered: about this matter, where different definitions have been given for "Rated Working Pressure" (RWP: 5000psi), "Maximum Operative Differential Pressure" (MDP: 3000psi) an Test Pressure (7500psi).

Differently from a flapper valve, for which the API 14A / ISO10432 standards allow a maximum leak of $5 \mathrm{scf} / \mathrm{min}$, Expro valve is designed for zero leak.

It closes within 40s without signal (fail-safe), but it can be forced to close in 20s with a dedicated signal.

\section{Geoservices Gem-Valve}

The GEM-Valve ${ }^{\mathrm{TM}}$ is a WSV developed by Geoservices and already being installed by other Companies.

The valve itself is an old field proven flapper type design, while the DHPU (Downhole Hydraulic Power Unit), the electronics and the batteries are added below (and for this reason it is not through bore). 
The valve is traditionally operated by hydraulic pressure, since the DHPU includes a pump that can pressurize the operating chamber. The electromagnetic technology is so retrofitted to a standard hydraulically operated SCSSV.

All the needed power is provided by the batteries, whose reliability and endurance is critical.

It can shut the well within 80 s (normally less).

The GEM-Valve ${ }^{\mathrm{TM}}$ is self equalizing, meaning that it can be open against pressure passing through an equalization position. Eni Policies prefer the SCSSV not to be self equalizing, but this preference is due to the risk associated with a failure to the hydraulic control system; these risks are not applicable for a WSV, for whom the selfequalizing feature is only an advantage.

\section{The Qualification Process}

The impossibility to straight apply iso 10432 / api 14 a procedures.

The SCSSV should be qualified following the International Standard ISO10432, which is the ISO equivalent to API 14A.

These EM WR-SCSSV, however, are based on a completely new technology which is not covered by ISO procedures.

In particular, the issues are:

- The impossibility to test the control line, since they are wireless controlled.

- The longest time required to close compared to the maximum allowed by the Standard (15s).

- The impossibility to drift the valves, since they are not through bore. 


\section{$\underline{\text { Iso Requirements }}$}

\section{The ISO 10432 foresees}

the possibility for a new technology

to be developed and, moreover, indicates the way to carry out the qualification of a SCSSV with such a new design. In fact in the introduction it states:

"Users of this International Standard should be aware that requirements above those outlined in this International Standard may be needed for individual applications. This International Standard is not intended to inhibit a supplier/manufacturer from offering, or the user/purchaser from accepting, alternative equipment or engineering solutions. This may be particularly applicable where there is innovative or developing technology. Where an alternative is offered, the supplier/manufacturer should identify any variations from this International Standard and provide details."
Again, at the point "e" of paragraph 6.5.2, the same International Standard defines:

"In the event that a particular SSSV has design or operational features which are incompatible with the test facility and test procedures required by this International Standard, the manufacturer shall advise the test agency as to the nature of the incompatibility and shall request and fully describe on the test application, or attachments thereto, any equipment or procedures required to test the SSSV.

Responsibility for furnishing, installing and testing this equipment shall be by agreement between the test agency and the manufacturer. The manufacturer shall be responsible for assuring that such equipment or procedures are not less stringent than this International Standard." 


\section{Eni's Way}

\section{TO fulfil the qualification's}

needs, Eni asked the suppliers to provide their procedures for qualification and function tests, which have been commented, modified and agreed jointly and the Test Agency's final report of qualification test.

Based on these documents, COMP did a technical evaluation for both the valves and issued the internal reports.

Both the EM WSV successfully passed Eni's technical evaluation.

Here below are reported the conclusions of each of the two above mentioned documents.

\section{$\underline{\text { Expro Flowcat }}{ }^{\mathrm{TM}}$ Technical}

\section{$\underline{\text { Evaluation's Conclusions }}$}

\section{The technical evaluation of}

all the above documentation can support Eni to declare:

The FlowCat ${ }^{\mathrm{TM}}$ SCSSV developed by EXPRO is an innovative tool, based on a new control technology and the ISO 10432 / API 14A Class 1 qualification process is not fully applicable.

The modified qualification procedure provided by EXPRO, with the clarifications added in the paper is as close as possible to the ISO 10432 procedure and the deviations adopted are technically justified. The FlowCat ${ }^{\mathrm{TM}}$ SCSSV S.N. 1 (first prototype) has successfully passed the full procedure defined as documented by the Test Agency.

The FlowCat ${ }^{\mathrm{TM}}$ SCSSV's tested design guarantees a theoretical reliability and safety standard higher than the current SSCSV's ones, although not as high as a TRSV's or a WR-SCSSV's.

The Functional Test Procedure and Form provided by Expro - Petrowell are as close as possible to the ISO 10432 and the deviations are the same applied in the modified qualification procedure. 
Geoservices gem-valve ${ }^{\mathrm{TM}}$ technical

evaluation's conclusions

\section{This is the final statement}

about the Geoservices GEM-

Valve $^{\mathrm{TM}}$ qualification process

The technical evaluation of all the above documentation can support Eni to declare:

The GEM-Valve ${ }^{\mathrm{TM}} \quad$ SCSSV developed by Geoservices is an innovative tool, based on a new control technology and the ISO 10432 / API 14A Class 1 qualification process is not fully applicable.

The modified qualification and function test procedure provided by Geoservics is as close as possible to the ISO 10432 procedure and the deviations adopted are technically justified.

The GEM-Valve ${ }^{\mathrm{TM}}$ SCSSV S.N. 002 has successfully passed the full procedure by the Test Agency.

The GEM-Valve ${ }^{\mathrm{TM}}$ SCSSV's tested design guarantees a theoretical reliability and safety standard higher than the current SSCSV's ones, although it's not as high as a TRSV's or a WR-SCSSV's.

\section{$\underline{\text { Field Trial }}$}

Having both the SCSSV qualified, Eni and STOGIT, proceeded with the field application for their final evaluation.

The plan was to run each valve in a flowing well and to leave it working for 6 months, with monthly tests. The two valves have been tested in the same well, to assure same environment conditions and comparable results.

STOGIT, interested in the project, has proposed the gas storage well San Salvo 54 in Fiume Treste field, as a good candidate for the installations. The valves have been interfaced with the standard remote control and ESD system and tested accordingly with the program. 


\section{Well Data}

$\mathrm{S}_{\text {an Salvo }} 54$ Dir is a gas storage well in Fiume Treste field, controlled by the plants of Cupello.

It was drilled in 1992 and the current TD is $1256 \mathrm{~m} \mathrm{MD}$. It was completed with 5" 15ppf J55 AMS tubings and open hole gravel pack, with VTL 7" 23ppf production packer at $1160.77 \mathrm{~m}$.

A Camco BA-6 3.812" x 3.75" Landing Nipple is located at $14 \mathrm{~m}$ from the $1^{\text {st }}$ flange. A SSD XA is at $1148 \mathrm{~m}$ from the $1^{\text {st }}$ flange.

This well has been considered a good candidate for the EMSCSSV application for the following reasons:

Its completion has a suitable size for the EM-SCSSV available.

Its design is very similar to other STOGIT's wells that can require this technology as a contingency (well with control line's failure) in the future.
Its production, although quite high, has not been considered critical for the whole field's performance (i.e. in case the SCSSV failed it was acceptable to keep the well close for sometime) Being a gas storage well, it allowed the SCSSV to be tested both in production and injection.

\section{Expro Flowcat Field Test}

On $17^{\text {th }}$ of September 2008 Expro engineers did a full site survey on the well and confirmed the suitability of the candidate.

The installation was planned to start on the $16^{\text {th }}$ of December.

On the $10^{\text {th }}$ of December 2008 the well was prepared by STOGIT with a redundant 2.75" $\mathrm{H}$ "Ambient" SSCSV set in the X profile at $1148 \mathrm{~m}$ below the $1^{\text {st }}$ flange (XA SSD).

\section{$\underline{\text { Installation }}$}

The surface equipment was prepared on the $16^{\text {th }}$ of December 
2008 as per Expro procedure. the control panel, which was placed

The anode was buried near the in the electrical cabin. electrical cabin and connected with

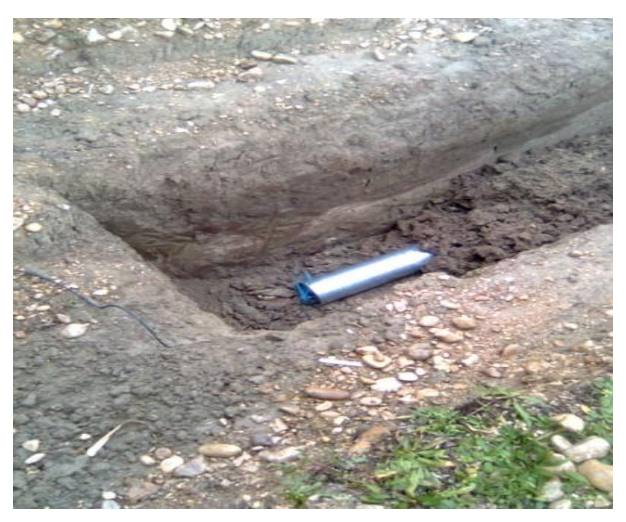

Fig.( 1) The earth anode.

An armed cable was set from it to the wellhead, where it was connected to the kill valve side's flange with a clamp.

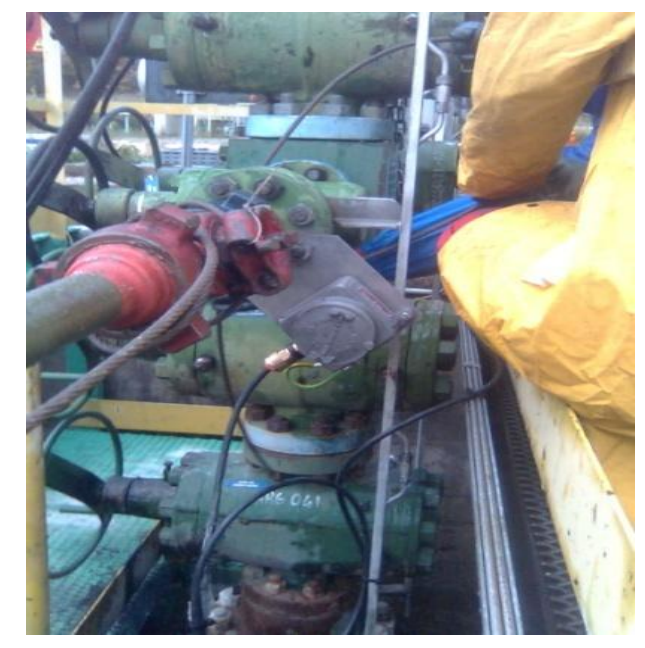

Fig.(2) The Connection At The Wellhead. 
Expro's control panel had been interfaced to STOGIT ESD system as per Expro Interface Specification "Interface of Expro Surface Transmitter to Stogit ESD system" rev. B (approved $6^{\text {th }}$ October 2008).

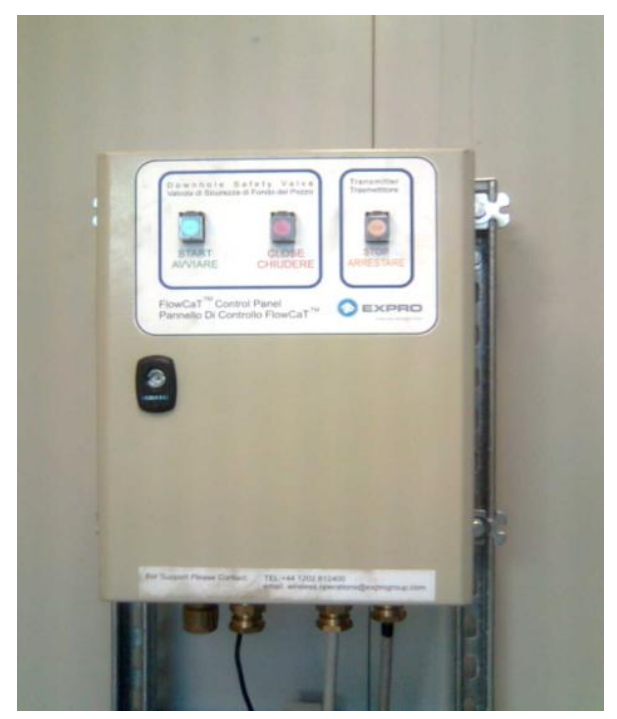

Fig.(3) The control panel.

A digital recorder was connected to the FlowCaT ${ }^{\mathrm{TM}}$ circuit and it was switched on to record the background noise all over the night. The well was so left in safety condition until the next morning.

On Wednesday 17th some tests were performed transmitting different status signals to the control room, with good results.

The SCSSV assembly (Camco BA-6 lock mandrel, equalizing sub, FlowCaT ${ }^{\mathrm{TM}}$ valve, battery pack and centralizer) was prepared. It was made up to the working string with a Camco PRS Running Tool and RIH. The weight was about 350lbs.

Reached the L.N., the Lock Mandrel was set jarring down. A pull test was performed up to $450 \mathrm{lbs}$, and then the Running Tool was disengaged with jar-up action and the string $\mathrm{POOH}$.

A 15min inflow test on the SCSSV seals and Lock Mandrel packings and o-ring with $\mathrm{THP}=75$ bar was performed with good results. 
On $18^{\text {th }}$, with the working and kill open, the THP measurement at the choke manifold was 72bar: no leak occurred on the SCSSV during the whole night.

After pressure tested the lines, the THP was increased up to $207 \mathrm{bar}$ (3000psi) by pumping nitrogen against the close EM SCSSV.

At 9:55 the OPEN signal was applied from the control panel and after about 10min (to be sure the valve was locked) the THP was bled down slowly to actually open the SCSSV. At about 1500psi the valve was seen to be open with good indication (pressure spike).

The well was flown to the flare for about $5 \mathrm{~min}$ to confirm the correct position of the valve and the correct status indication in the control room was checked.

At 10:30 the EM SCSSV was closed by the STOGIT ESD panel: the Expro panel switched in the valve was supposed to "close" position (red light) then it closed in $\max 20 \mathrm{~s}$.
The THP was slowly bled, but it showed a build up trend up to 106bar (STHP). An attempt was made to bleed the pressure more quickly down to 40bar and, after that, it stayed stable, giving a good closure indication.

The THP was later bled off to 0 to perform a $15 \mathrm{~min}$ inflow test: no leak was detected.

At the control room the valve's status was correct (“CLOSE”).

After this good cycle, a new one was started building up the pressure to 207bar (3000psi) with nitrogen pump. At 11:10, after the ESD reset, the "OPEN" signal was applied by Expro control panel and the THP was bled. Once again, at about 1500 psi there was good signal of open position and a short flow to the flare was done to confirm it. At the control room they correctly read the "OPEN" position.

At 11:30 the "STOP" button on Expro panel (equivalent to a power shut down) was pushed: the valve 
should close in max 40s (fail-safe closure).

The THP was bled off to 0psi and a 15min inflow test had good results. The status at the control room was checked to be right.The EM WR SCSSV was opened once again applying 207bar (3000psi) at wellhead, pushing the "OPEN" button and bleeding the THP again.

At about 1500psi the SCSSV was open and a short flow to flare was allowed.

At 12:00 the well was opened in flow line and the control room informed about a flow rate.

At 14:00 the well was shut in at the surface and given to Production Department and all the Service Companies' equipment was rigged down.

\section{Monthly Tests}

\section{The EMSV has been}

tested once a month for six months during the normal exercise of the well. The first test was done just after the installation, while the final one was done right before the pull out of hole.

The procedure for each test, accordingly with OPERATIVE TEST PROGRAM FOR EMSCSSV EXPRO FLOWCATTM prepared by Eni was:

Monitor and record the FTHP for $15 \mathrm{~min}$.

Close the well at wellhead.

Monitor and record the STHP for $15 \mathrm{~min}$.

Close the FlowCaT ${ }^{\mathrm{TM}}$ SCSSV as per Expro procedure. Wait at least one minute after the control signal is removed to allow the valve to close.

Bleed the STHP to zero or to the flowline pressure. Monitor and record STHP for $15 \mathrm{~min}$. If the pressure is increasing, check for the leak rate: if it is greater than $15 \mathrm{scf} / \mathrm{min}$, the valve fails the test.

Pressurize the string to equalize pressure at SCSSV's depth. Increase the pressure adding 15002000psi and open the FlowCaT ${ }^{\mathrm{TM}}$ 
valve as per Expro procedure (Nitrogen pumping unit required).

Restore original well conditions as per Stogit requirements.

During all the above steps, the status of the WSV was monitored by the STOGIT control room in the central plant.

As said, the first test was done on $18^{\text {th }}$ December after the installation.

The next tests were every month for other 5 time. All the above tests were successful.

Just before pulling out the SCSSV, about 6 months after the installation, the final test was performed. This was decided to be a slam test (i.e. valve's closure with flowing well), to stress the shutting device as much as possible.

The slam test and the final inflow test were successful, with zero leak recorded.

The slam test was performed about $49000 \mathrm{Sm}^{3} / \mathrm{d}$ of gas rate and the estimated closure time of the poppet was about 20s.

\section{$\underline{\text { Evaluation }}$}

AS for the above described process, the 3.65" Expro FlowCaT ${ }^{\mathrm{TM}}$ EM WR-SCSSV has been successfully installed, tested and pulled in an active STOGIT's gas storage well.

Three (3) unplanned closures of the SCSSV was happened (fortunately during well's shut in periods) because of human errors (i.e. the Production Operators operated the ESD system/control panel unproperly). Anyway the SSV always operated properly.

The final inspection performed by Petrowell confirmed the good status of the valve, with minor wear on the moving parts within the exepctations.

The battery worked properly and was extimated to have some 6-8 weeks of life left. 
The FlowCaT ${ }^{\mathrm{TM}}$ EM SSV is

surface controlled.

It is fail safe.

It can be interfaced to any standard ESD system.

It is designed for "zero leak".

Being poppet type instead of flapper type, it can probably and effectively perform more than one "slam" test without a need of pull out of hole.

It closes in 40s "fail safe", but this time can be reduced down to 20 s with the dedicated signal.

The FlowCaT ${ }^{\mathrm{TM}}$ EM SCSSV requires 1500-2000psi above the shut in pressure to re-open (to be applied with nitrogen unit or equivalent system).

And demands Extra costs for dedicate equipment and operation (e.g.: nitrogen and pumps) to reopen the valve.

Time required to re-open the valve.Wellhead's pressure rating shall be evaluated.
The closure time is not as short as the hydraulic SCSSV's one.

The personnel shall be clearly instructed about EM SSV operating procedures to avoid accidental closures.

\section{$\underline{\text { Geoservices Gem-Valve }{ }^{\mathrm{TM}} \text { Field }}$}

$\underline{\text { Test }}$

The GEM-Valve ${ }^{\mathrm{TM}}$ was

officially accepted by Eni.

The 3.72" GEM-Valve ${ }^{\mathrm{TM}}$ marked with s.n. 002 was function tested in Geoservices facilities in Paris on $14^{\text {th }}$ and 15 h May 2009 as per agreed procedure .

On 4th June 2009 a meeting with STOGIT, COMP and Geoservices was held in San Salvo to evaluate the installation's requirements and feasibility. The same day Geoservices engineers did a full site survey on the well .

The installation was planned to start on $30^{\text {th }}$ June 2009.

On $30^{\text {th }}$ June 2009 the well was prepared by STOGIT, removing the 
Camco BA-6 hydraulically the surface equipment was controlled SCSSV and installing a prepared on $30^{\text {th }}$ June 2010 as per redundant 2" $\mathrm{H}$ "Ambient" SSCSV agreed plan and the control panel set in the 2.75 " X profile at $1148 \mathrm{~m}$ below $1^{\text {st }}$ flange (XA SSD).

\section{$\underline{\text { Installation }}$}

\section{Before the EM SCSSV}

installation intervention, the well was interfaced to STOGIT ESD system.

The anode was buried near the electrical cabin and connected with the control panel, which was placed was shut in at surface. The STHP was 101 bar (1464psi).

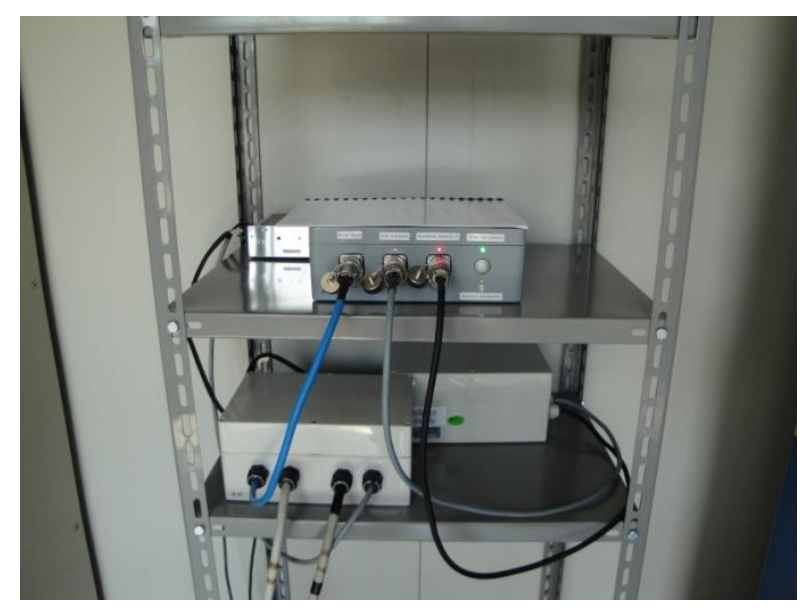

Fig.(4) GEM-Valve ${ }^{\mathrm{TM}}$ 's control panel.

An armed cable was set from it to the wellhead, where it was connected to the kill valve side's flange with a clamp.

A digital recorder (Manorecorder from Stogit) was connected downstream the Flow Wing Valve to record the pressure data.

On Wednesday $1^{\text {st }}$ July, the EMSCSSV was run in hole.

Reached the Camco BA-6 L.N. at 23,8m RKB, the Lock Mandrel was 
set jarring down. A pull test was performed then the PRS Running Tool was disengaged with jar-up action and the string $\mathrm{POOH}$.

The Master Valve and the Working Valve were partially closed to avoid damages to the tree in case of failure of the Lock Mandrel and the THP was bled down to 50bar through the HP flex hose.

A 15 min inflow test on the SCSSV seals and Lock Mandrel's packings and o-ring was performed with good results.

OPEN signal was applied from the control panel and after about 100s the THP started to increase due to the equalizing position reached by the flow tube.

Once completed the equalization, waited 5 minutes to allow the valve to open completely, the well was opened to confirm the correct position of the valve and the correct status indication in the control room was checked.

EM SCSSV was closed by the STOGIT ESD panel: the
Geoservices panel switched in "CLOSE" position and the valve was supposed to close in max $55 \mathrm{sec}$. WHP was slowly bled off to 0 to perform a $15 \mathrm{~min}$ inflow test: no leak was detected.

At the control room the valve's status was correct ("CLOSE").

After this good cycle, the button on the STOGIT ESD panel was reset and the OPEN signal was applied from the control panel. After about 100s, the THP started to increase due to the equalizing position reached by the flow tube.

The well was slightly flown to verify the WSV was actually open and the control room informed. After the final checks, all the Service Companies equipment was rigged down, the Christmas Tree's valves were opened and the well handovered back to STOGIT for gas injection.

\section{Monthly Tests}

The EMsv has been tested once a month for six months during the normal exercise of the 
well. The first test was done just after the installation, while the final one was done right before the pull out of hole.

The procedure for each test, accordingly with OPERATIVE TEST PROGRAM FOR EMSCSSV GEOSERVICES GEMVALVE $^{\mathrm{TM}}$ prepared by Eni, was:

Monitor and record the FTHP for $15 \mathrm{~min}$.

Close the well at wellhead (Stogit personnel will be in charge for this operation).

Monitor and record the STHP for $15 \mathrm{~min}$.

Check the SCSSV status displayed at Stogit Control Room. Close the Gem-Valve ${ }^{\mathrm{TM}}$ SCSSV as per Geoservices procedure. Wait at least one minute and a half after the control signal is removed to allow the valve to close.

Check the SCSSV status displayed at Stogit Control Room.

Bleed the STHP to the flowline pressure or to a suitable value to check for the leak rate (in any case no higher than $50 \%$ of previously recorded THP). Monitor and record STHP for $15 \mathrm{~min}$. If the pressure is increasing, check for the leak rate: if it is grater than $15 \mathrm{scf} / \mathrm{min}$ (ref. to ARCO-P-1-S20014), the valve fails the test.

Open the Gem-Valve ${ }^{\mathrm{TM}}$ as per Geoservices procedure.

Check the SCSSV status displayed at Stogit Control Room.

Restore original well conditions as per Stogit requirements.

As said, the first test was done on $1^{\text {st }}$ July 2009 after the installation.

The next tests were every mounth for other 5 time. All the above tests were successful.

All the above tests were successful.

Just before pulling out the SCSSV, on $12^{\text {th }}$ January, the final test was performed. This was decided to be a slam test (i.e. valve's closure with flowing well), to stress the shutting 
device as much as possible. The $\underline{\text { slam test and the final inflow test }}$ were successful.

The slam test was performed about $51000 \mathrm{Sm}^{3} / \mathrm{d}$ of gas rate and the estimated closure time of the flapper was less than 90s (i.e. the FTHP dropped after about 90s).

\section{$\underline{\text { Evaluation }}$}

As for the above described process, the 3.72" Geoservices GEM-VALVE ${ }^{\mathrm{TM}}$ EM WR-SCSSV has been successfully installed, tested and pulled in an active STOGIT's gas storage well.

The final inspection performed by Geoservices confirmed the good status of the valve.

The battery worked properly and allowed to perform other 4 extra cycles after the valve had been pulled out of hole (17 total cycles completed totally).

\section{The GEM-VALVE ${ }^{\mathrm{TM}}$ EM SSV} is surface controlled. It is fail safe.
It can be interfaced to any standard ESD system.

It is self equalizing.

It doesn't need any intervention on the well to re open: it can be opened just pressing the button on the control panel.

Being flapper type, it is not designed for 0 leak; however it always performed within ISO / API requirements and withstood the slam test.

The closure time is longer than the hydraulic SCSSV's one.

The personnel shall be clearly instructed about EM SSV operating procedures to avoid accidental closures.

\section{$\underline{\text { Conclusions }}$}

After a strict "ISOmodified" qualification process and a 6-months field installation in a STOGIT gas storage well with monthly tests and a final slam test, both the considered Electromagnetic 
Wireless Surface Controlled Subsurface Safety Valves:

$$
\text { Expro 3.65" FlowCaT }{ }^{\mathrm{TM}}
$$

Geoservices 3.72" GEM-VALVE ${ }^{\mathrm{TM}}$

are considered qualified and field proven to be installed in eni wells.

They can be considered as the third option to maintain the well's safety, when a Tubing Retrievable (TR) hydraulically controlled SCSSV (first option) has failed and the Wireline Retrievable (WR) hydraulically controlled SCSSV (second option) is not applicable (i.e. failure at the hydraulic control system).

The EM WR-SCSSV shall be preferred to the Sub-Surface Controlled Safety Valves (SSCSV), since they are surface controlled and fail safe, meeting eni's policies.

The WSV can and shall also be installed in the old wells completed without a hydraulic control line. 


\section{$\underline{\text { References }}$}

1. ISO 10432 third edition (2004-12-15) Petroleum and natural gas industries Downhole equipment - Subsurface safety valve equipment API Spec $14^{\circ}$ Specification for subsurface safety valve equipment. 